\title{
REFLECTIONS ON THE EPIDEMIOLOGY OF GONORRHOEA*
}

\author{
BY \\ A. GRIMBLE \\ Guy's Hospital, London, S.E.I
}

The plasticity of the instinctual tendencies is the condition of cultural advance.
Malinowski: Sex Repression in Savage Society

Every age lives by the energies which have sprung from its thought about ethics.

Schweitzer: Civilization and Ethics

In any discussion about $N$. gonorrhoeae and its human host, one aspect of it holds our attention above others: the organism is transmitted by sexual intercourse in almost all cases and depends upon promiscuous sexual behaviour for its spread in the human community. Principally therefore we wish to know about the organism and the sexual habits of its human host in order to understand the epidemiology of the disorder "gonorrhoea". In investigating human sex behaviour, however, one has to be wary of subjective attitudes, either of a too loose and lenient liberalism or of a too rigid and moralizing puritanism. The subject will be discussed in three parts: (1) general and more specific aspects of the epidemiology of gonorrhoea, (2) sexual behaviour, and (3) the role of the gonococcus.

\section{Epidemiology}

Epidemiology has been defined as the science of the total phenomenon of infectious disease (Jameson and Parkinson, 1930), wherein we discover its prevalence, variation, and periodic recurrence. We have to consider such factors as environmental changes, susceptibility, introduction of infection from outside a population group, infectivity of the organism, and alteration in methods of transmission

* Based on a lecture given at Guy's Hospital; received for publication May 25, 1964. and behaviour of the persons at risk. This information must perforce include much that is of social significance. This aspect of epidemiology borders on social medicine, which has been defined as the study of ill-health inherent in the structure of a society, in the domestic and personal habits of its members, and in the way of living and the working conditions of the community; also-and perhaps not least-in the philosophical and religious attitudes which govern, consciously or unconsciously, an individual's conduct (Frazer Mackenzie, 1947).

The incidence of gonorrhoea rises with periods of social unrest (Fig. 1). That this can happen in almost any country can be seen by studying the trends elsewhere. The recent trends since 1950 for several countries are shown in Fig. 2 (opposite). There has been a general increase in this infection, showing that it is not a phenomenon confined to any particular part of the globe. In previous years frustration, boredom, lack of a fixed job, and economic uncertainty, were the backgrounds to the peaks of 1929-30 and 1946. The recent increase has occurred for reasons not so apparent, and it has aroused some discussion.

If there are some countries which seem to come off better than others, this is possibly due in part to the efficiency of their public health services. Those countries most candid about the size of the problem,

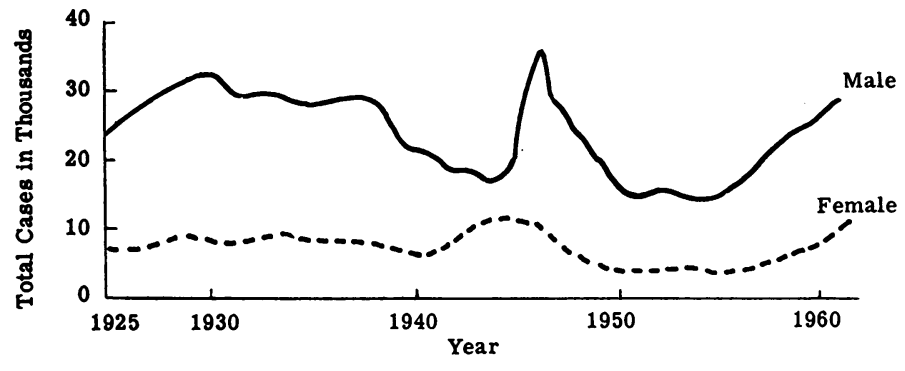

FIG. 1-Incidence of gonorrhoea in England and Wales, 1925 to 1960 , by sex. During this period total population increased by 29 per cent. 


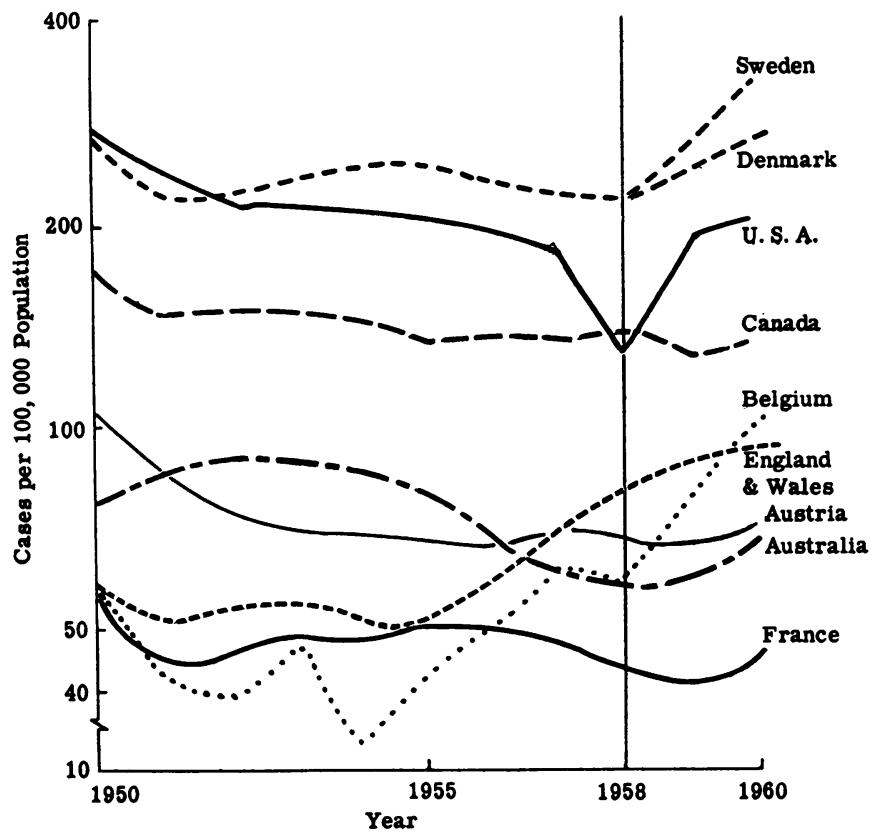

FIG. 2.-Incidence of gonorrhoea per 100,000 population in nine countries, 1950 to 1960.

such as Denmark, appear to be worse off than, for example, the USSR, where few figures are published and discussion assumes a propaganda character. Not all cases are registered in Great Britain and a significant number are treated privately by general practitioners and are not recorded officially.

When we consider the age of those infected, it must be remembered that this is a disorder closely related to potency, and will therefore always be commoner in the younger age groups. Figures for the age of patients have not so far appeared in the official returns. Prebble (1962) has given us figures from the Liverpool Royal Infirmary for 1935 and 1960. (The figures refer to all infections, but the gonorrhoea figures will set the pattern, always). It should be noted that the two groups are not strictly comparable, the under-20 group for 1960 containing one more year than the similar group for 1935. Fig. 3

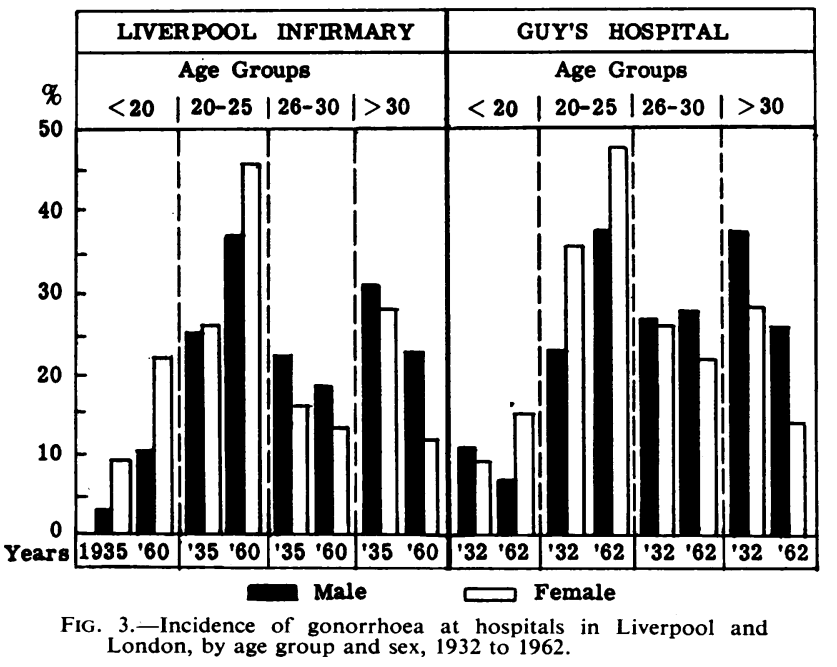


compares Prebble's figures with those from Guy's Hospital for the years 1932, 1942, and 1962. The figures suggest that there has been a shift, and that there is now more infection in persons aged 25 years and under, than in the over-25's (although in this department there was half as much gonorrhoea again in 1932 as in 1962).

Prebble (1962) states that, from the foregoing evidence, there can be no doubt that the teenager of to-day is more promiscuous than the teenager of a quarter of a century ago. It is doubtful whether one can be so dogmatic from the given evidence, especially when one considers the great social changes which have taken place, the more healthy state of youth, and the earlier occurrence of puberty. The increase in gonorrhoea is not confined to the teenager, be it noted, but to the younger group-that is, the preponderantly unmarried group.

The rise is certainly steeper in some countries, and particularly in Denmark, where 1 per cent. of all 15 to 19-year-olds have gonorrhoea, and where in 1961 83 per cent. of girls with gonorrhoea were in this age group compared with under 20 per cent. in 1944 (WHO, 1963).

When we consider the sex differences the figures demonstrate what has always been known, that gonorrhoea is less common in the female but relatively commoner in the young female, facts explained by the aggressive sexual habits of the male and the younger age of puberty in the female. There is also a clear difference in the clinical problem. Whereas in men the clinical diagnosis is often straight-forward, in women the opposite is usually the case. Women all too often, therefore, remain carriers of the disease.

There appear to be few racial, religious, or national factors which have any significant effect on the incidence of gonorrhoea. Racial differences in attitude to infection such as this are of course marked, from the striking matter-of-factness of some to the almost neurotic secrecy of others. But the disease presents itself in both sorts, and is merely harder to estimate in the latter.

An important factor in transmission is the movement of individuals or peoples. In an era of rapidly increasing travel this factor is unlikely to diminish in either size or extent. It includes the movement of working groups, immigrants, servicemen, and individuals at work or on leave, and has as its basis the very human aspects of loneliness on the one hand and happy release from frustration and irksome discipline on the other. The movements of workers who follow seasonal agricultural occupations have presented a serious problem to the US public health authorities, particularly those across the Mexican border. In Great Britain with its predominantly urban population and mixed groups, the problem is always arising (Jefferiss, 1963). Immigrants, therefore, will alway show a higher rate of infection, as they have done in Great Britain in the past decade. The same effect can be seen for instance in the demonstration by Morton (1963) of the occurrence of local epidemics in Yorkshire where road-building projects had attracted Irish workers. Likewise, the Medical Officer of Health for Jersey (1963) was able to state that the venereal infection rate for the island had increased enormously because of visitors from England.

\section{Sexual Behaviour}

Quite apart from certain situations which appear to aggravate sexual promiscuity, there is an undertone of bad sexual habits in society as a whole which requires study, if we are not to lose our sense of direction and balance in this matter.

It is only too easy from the entrenched position of middle age to adduce that all is wrong with the youth of to-day. Nicol (1963) spoke recently at a Washington symposium condemning teenage morals (in England) and almost whitewashing the gonococcus. The Chief Medical Officer of the Ministry of Health likewise talked of a "social malaise" among the young in this question of sexual attitudes, and a recent BMA publication implies that we have reached the position of having to make a choice between liberalism and chastity.

What are the facts of the case, and is it ever likely that promiscuous sexual behaviour will completely cease? By a promiscuous sexual relationship we mean one where there is a light-hearted and fleeting attachment.

The patterns of sexual behaviour and the attitudes to them of many tribes, peoples, and ethnic groups from the most primitive to the most sophisticated have been studied by Ford and Beach (1952). Premarital promiscuity among more primitive but monogamous communities is common. It is often accepted, and where it is not accepted most parents will raise no objections provided an affair is kept secret. Marriage is soon arranged if pregnancy should arise. In many such societies a high ideal of pre-marital chastity is affirmed, but only rarely is it upheld in practice. 39 per cent. of 139 groups of peoples studied approved of some sort of sexual relationship outside marriage or mateship. In many more it was accepted by individuals that a loveaffair should take place but that it should be discreet. The range of attitudes was not much different from that which one would find in most present-day sophisticated societies. 
On the role of chastity and its relationship to type of culture, the treatise of Unwin (1934) is worth recalling. He observed that chastity, or the limiting of sexual activity by some sort of compulsory sexual continence (by social or religious taboos), induces in that society, out of the emotional conflicts which arise, a social energy which is displayed in new ideas. A second dimension is added when this "painful event" of continence is accompanied by prenuptial chastity. This leads to, or tends to occur within, a deistic cultural tradition. Unwin completes his argument by showing that when rigour in these matters slackens and the sexual opportunities of society as a whole are extended, that society begins to display less energy. If however the sexual opportunity of future generations is restrained to a minimum, further cultural changes occur and there is a more marked sense of inquiry and realism.

Anthropologically, therefore, there seems to be a good case for sexual continence. Whether there has been any radical alteration in the pattern of sexual behaviour remains an open question. Everyone knows that certain individuals are more apt to undertake light-hearted sexual relationships than others, especially when away from the ties of a settled community life. It is very difficult to believe that man has fundamentally changed in this respect. These habits are very much a part of an individual's outlook on life. The fact that to-day there may be a less favourable milieu (sic) for the formation of the highest number of stable sexual relationships is a matter of social as well as individual responsibility. But having said this one is forced to recognize that the bewildering number of influences bearing on this problem make their objective analysis impossible. Is it possible to state as some would imply that a serious deterioration in sexual habits has been responsible for the rise in incidence of gonorrhoea? (Grimble, 1965).

It is difficult to obtain a clear notion of the normal pattern, let alone measure change. In a severely moralizing tract, Mackenzie (1947) sought collateral evidence and has been followed by other authors. The only attempt at an objective study has been that of Kinsey and his colleagues (1953). As a main criticism one might quote Kinsey's own words: "We are not sure that we can completely comprehend why people have been willing to talk to us." However, the study drew attention to the important fact that sexual activity will certainly take place whatever the restrictions placed on it. Late marriage and earlier adolescence will result in one or more of four choices: monogamous sexual relationships, sexual abstinence with successful sublimation, abstinence with neurosis, or irregular sexual relation- ships. Briefly, Kinsey stated the facts and found them to be not new: in the United Stated nine out of ten males had had coitus by the age of 25 years, whereas half were unmarried at 26,85 per cent. of the population accepted pre-marital coitus. Extra-marital coitus was commoner in the lower educational group soon after marriage but commoner in the higher educational group later in marriage. Virginity was held to be important in one's fiancée even by the most promiscuous. Relatively few women had frequent intercourse outside marriage: the figures given are 35 per cent. by the age of 25 years in contrast with 90 per cent. of males. The figure for extra-marital coitus in the female rose from 8 per cent. at 25 years to 22 per cent. at 35 years.

When the report compared the behaviour of males of the present generation with that of males of the previous generation, only one significant difference was found, that the previous generation consorted more with prostitutes and the present one more with girl-friends. At Guy's in 1963, 12 per cent. of men with gonorrhoea had aquired it from prostitutes as against just under 20 per cent. for the year 1933. There are no comparable figures to the American ones.

In Great Britain, Frazer Mackenzie (1947) inveighed against the lowering of moral standards and said that juvenile crime, alcoholism, venereal disease, illegitimacy, and so on, would rise with the increase in dishonesty, loosening of family ties, and proliferation of obscene reading matter.

Fig. 1 (above) shows that, whereas the population had risen by 29 per cent. between 1925 and 1962, the incidence of infection had not risen. One might even say that, compared with the rise in population and indictable offences (Figs 4 and 5, overleaf), infection had remained steady or declined.

Similarly, the figures for illegitimacy are of little help. The rate depends to an unknown extent on the customs prevailing at any time. Conception before marriage is known to be not uncommon, and has always been so. The slight rise which has been noted during the past year or two may, in the light of the enormous social changes which have taken place during the past years, reflect the fact that fewer young girls have been dragooned into marriage on the discovery of pregnancy.

It is easy to jump to conclusions in these matters. These figures can be used to support different viewpoints: they might just as well suggest to us that our young men are healthier, better developed, and more active and aggressive and wide-ranging in society, certain aspects of which qualities in certain sections of the population will be reflected in the rates of indictable offences and venereal disease. It is no truer 


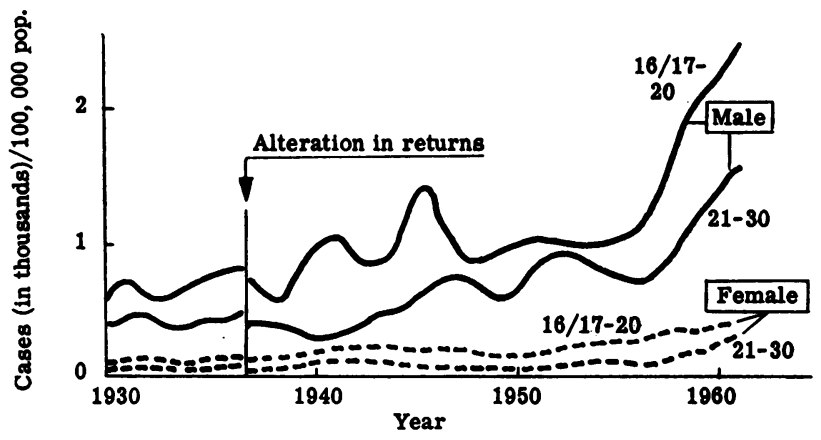

FIG. 4.-Incidence of indictable offences per 100,000 population, by sex and age group, 1930 to 1960.

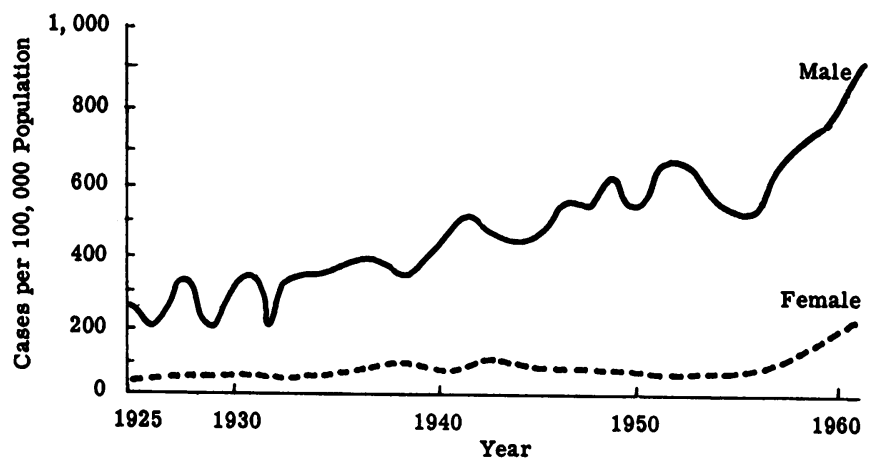

FIG. 5.-Incidence of indictable offences brought before the courts per 100,000 population, by sex, 1925 to 1960 .

to state that these figures must reflect idleness, lawlessness, and other forms of insensitive depravity. It is but a short time since young women have won the same freedom in society as that accorded to their brothers, and it would be expecting a great deal to hope that venereal infection ceased to coexist with such a profound social change. Our society is too diversified and subject to too many pressures for it to be possible to state with any certainty that there exists a wholesale freeing of sexual opportunity such as Unwin concluded to have occurred in certain societies. By and large, for example, England did not seem to have been morally or intellectually much the worse for the freedom which ensued with the restoration after the very different climate of the Puritans under the Protectorate. In this matter of sexual behaviour we need a sense of proportion.

To conclude on the evidence of Figs 1, 4, and 6. If the actual increase in gonorrhoea does not seem to be so serious when the rise in population is taken into consideration, what of the significance of the increase in the younger age groups? Here again we must take the broad view and consider it in relation to society as a whole. The increase, as we have shown, is limited to the under-30 age group, sexually the most potent group. Types of behaviour in the individual will vary according to age; can it be said that the over-30 age groups indulging in fatuous games and other un-moral occupations have any right to blame those whose energies and youth naturally direct them to sexual matters? The one is as easily criticized as the other.

On the matter of increase in indictable offences, the figures will reflect in part several factors: actual

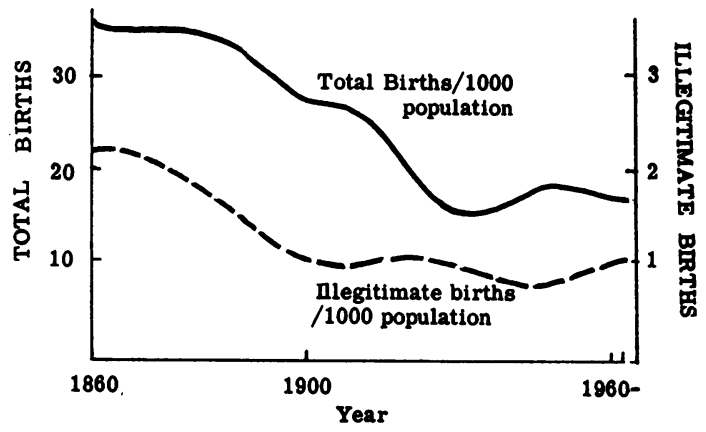

FIG. 6. - Incidence of illegitimate births as proportion of total births per 1,000 population, England and Wales, 1960 to 1961 . 
offences, offences considered by society at any one time to be indictable, offences so considered over the years by magistrates-thus moulding opinion and altering police attitudes to the offenders whom they pick-up - and the attitude of the law itself.

It is therefore extremely difficult to arrive at a balanced view, and easy to accept uncritically the superficial trends shown in Figs 4 and 5. The fact is that the rise has been fairly steady until quite recently, almost entirely confined to males, and not occurring especially among teenagers. This is society's problem as a whole, with its question of tensions, frustrations, and ideals or goals within society itself, and it seems fruitless to foist the blame for its errors on to any one section.

Lastly, it is quite impossible to state whether the small rise in illegitimate births is real or apparent, since the very word "illegitimate" begs the question of where the line is to be drawn-at conception, at birth, or at what interval after birth?

\section{Bacterial Factor}

When we consider the role of the organism itself, it is apparent that the rise in the incidence of the infection has more in common with a rise in insensitivity of response by the organism to drug treatment than to other factors. Resistance has been gathering momentum since it was first demonstrated in the middle of the last decade.

It is known that, if a number of cases of an infectious disease remain uncured and uncontained, the incidence of that infection is almost certain to rise. A comparison of Fig. 2 with Fig. 7 shows the trend of the minimum amount of penicillin required to treat an acute case of gonorrhoea between the years 1950 and 1963 . The curve closely follows that of the increase in incidence since the year 1950 (shown in Figs 1 and 2). It is considered (WHO, 1963) that failure rates for the treatment of gonorrhoea lie between $1: 6$ and 1:10, through micro-organism resistance, failure of the drug to reach the site, and so on. There can be no doubt that the sensitivity of $N$. gonorrhoeae is changing at a significant rate, and where no in vitro studies are carried out it is clear that larger doses of penicillin have to be used to cure the infection.

Clearly, therefore, small differences in sensitivity will result in many patients being symptom-free but not cured. Recent surveys of strains sent to Copenhagen from such widely separated sources as West Africa, Ceylon, the Philippines, and Poland showed that in West Africa nearly 100 per cent. were sensitive to all the usual antibiotics, that in the Philippines 100 per cent. were less sensitive to penicillin ( 59 per cent. less to streptomycin and 49 per cent.

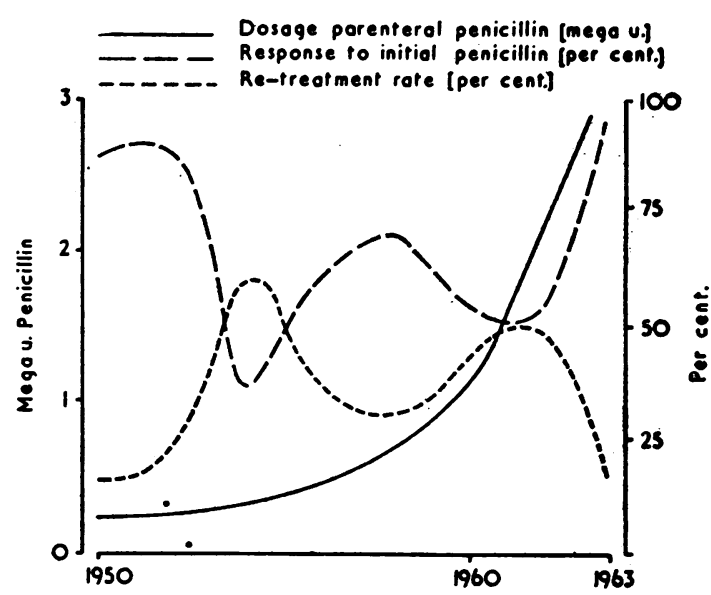

FIG. 7.-Percentage response to initial pencillin, retreatment rate, and size of penicillin dosage, 1950 to 1963.

less to tetracyclines), and that in other areas sensitivities occupied an intermediate position. Is there any wonder that there is an almost world-wide increase in gonorrhoea?

The importance of this is realized when it is known that the majority of women infected are either symptomless or unaware of the nature of their symptoms. A carrier state may occasionally occur in men but this is rare. Nicol (1948) found that over half the women who attended with gonorrhoea stated at the time that they had no symptoms; and one observer in the USSR is quoted as saying that only one in ten women with gonorrhoea had symptoms.

The complications of this disease have been less frequent in recent years, and this trend was noted even before the full advent of antibiotics. In males the rate is considered to be about 3 per cent. in the immediate post-infective period. Later effects, such as prostatitis or stricture, may account for a few more.

In women the rate is said to be at least 10 per cent. Residual symptoms which cleared up with no evidence of prolonged infection occurred in about 15 per cent. of cases in our experience, the rate for the severer type of complication being about 3 per cent.

\section{Conclusion}

There are necessarily limitations in our knowledge, but it seems doubtful whether the habits of human beings have changed radically, certainly not as much as the considerable changes in the manner in which the gonococcus responds to the many drugs, from the sulphonamides onwards, that may be used in treating the infection. 


\section{Summary}

This paper contains a short review of the factors which enter into the aetiology of an infection such as gonorrhoea, and an attempt is made to assess the significance of some of these factors. It is pointed out that, in recent years, the social factors have tended to be stressed more than the biological ones in any discussion of the epidemiological aspects of gonorrhoea; in particular, one age group in society is singled out for censure without a balanced appraisal of the whole social environment.

\section{REFERENCES}

Ford, C. S., and Beach, F. A. (1952). "Patterns of Sexual Behaviour". Eyre and Spottiswoode, London.

Grimble, A. (1965). Excerpt. Criminol., July.

Jameson, W., and Parkinson, G. (1930). "Synopsis of Hygiene", 3rd ed. Churchill, London.

Jefferiss, J. (1963). Brit. med. J.

Kinsey, A. C., Pomeroy, W. B., and Martin, C. E. (1948). "Sexual Behaviour in the Human Male". Saunders, Philadelphia.

, , and Gebhard, P. H. (1953). "Sexual Behaviour in the Human Female". Saunders, Philadelphia.
Mackenzie, I. Frazer (1947). "Social Health and Morals". Gollancz, London.

Medical Officer of Health, Jersey (1963).

Morton, R. S. (1963). Brit. J. vener. Dis., 39, 105.

Nicol, C. S. (1948). Ibid., 24, 26. (1963). Ibid., 39, 168.

Prebble, E. E. (1962). Ibid., 38, 86.

Unwin, J. D. (1934). "Sex and Culture". Oxford University Press, London.

WHO (1963). "Expert Committee on Gonococcal Infections. First Report". Tech. Rep. Ser., No. 262. WHO, Geneva.

\section{Réflexions sur l'épidémiologie de la gonorrhée \\ RÉSUMÉ}

Dans cet article, on passe rapidement en revue les facteurs étiologiques de la gonorrhée et on essaie de déterminer la signification de quelques uns de ces facteurs. On fait remarquer que, ces dernières années, dans toutes discussions épidémiologiques, on a eu tendance à mettre l'accent plus sur les facteurs sociaux que sur les facteurs épidémiologiques de la gonorrhée; en particulier, on stigmatise un groupe selon l'âge dans la societé, sans équilibrer cette condamnation par une juste appréciation de tout le contexte social. 